\title{
Paraptosis and NF-KB activation are associated with protopanaxadiol-induced cancer chemoprevention
}

\author{
Chong-Zhi Wang ${ }^{1,2}$, Binghui Li ${ }^{3}$, Xiao-Dong Wen ${ }^{1,2}$, Zhiyu Zhang ${ }^{1,2}$, Chunhao Yu ${ }^{1,2}$, Tyler D Calway ${ }^{1,2}$, \\ Tong-Chuan He $\mathrm{He}^{4}$, Wei Du ${ }^{3}$ and Chun-Su Yuan ${ }^{1,2,5,6^{*}}$
}

\begin{abstract}
Background: Protopanaxadiol (PPD) is a triterpenoid that can be prepared from steamed ginseng. PPD possesses anticancer potential via caspase-dependent apoptosis. Whether paraptosis, a type of the caspase-independent cell death, is also induced by PPD has not been evaluated.

Methods: Cell death, the cell cycle and intracellular reactive oxygen species (ROS) were analyzed by flow cytometry after staining with annexin V/PI, PI/RNase or H2DCFDA. We observed morphological changes by crystal violet staining assay. Mitochondrial swelling was measured by ultraviolet-visible spectrophotometry. The activation of NF-kB was measured by luciferase reporter assay.

Results: At comparable concentrations of 5-fluorouracil, PPD induced more cell death in human colorectal cancer cell lines HCT-116 and SW-480. We demonstrated that PPD induced paraptosis in these cancer cells. PPD treatment significantly increased the percentage of cancer cells with cytoplasmic vacuoles. After the cells were treated with PPD and cycloheximides, cytoplasmic vacuole generation was inhibited. The paraptotic induction effect of PPD was also supported by the results of the mitochondrial swelling assay. PPD induced ROS production in cancer cells, which activated the NF-KB pathway. Blockage of ROS by NAC or PS-1145 inhibited the activation of NF-KB signaling. Conclusions: PPD induces colorectal cancer cell death in part by induction of paraptosis. The anticancer activity of PPD may be enhanced by antioxidants such as green tea, which also inhibit the activation of NF-KB signaling.
\end{abstract}

Keywords: Ginseng, Protopanaxadiol, PPD, Paraptosis, Cytoplasmic vacuoles, Mitochondrial swelling, Antioxidant, Cancer chemoprevention

\section{Background}

The clinical management of cancer invariably involves diverse conventional modalities, including surgery, radiation, and chemotherapy [1]. Because of the complexity of human cancer, alternative management may be needed to improve the efficacy of therapeutic treatments and the quality of life of patients [2]. Cancer chemoprevention or treatment may combine natural products with chemotherapeutic agents to inhibit tumor development [3-5]. Natural products have been shown to be one

\footnotetext{
* Correspondence: CYuan@dacc.uchicago.edu

'Tang Center for Herbal Medicine Research, University of Chicago, Chicago, IL, USA

2Department of Anesthesia and Critical Care, University of Chicago, Chicago, IL, USA

Full list of author information is available at the end of the article
}

option for cancer chemoprevention and new drug development [6-8].

Long-term consumption of certain botanicals, such as ginseng, is associated with a reduction in cancer incidence in humans $[9,10]$. Anticancer potential has been observed with ginseng and its compounds, including the enhancement of 5-fluoruracil's anti-proliferative effects on human cancer cells [11-13]. Steaming ginseng changes its ginsenoside profile and increases its anticancer potential $[14,15]$.

The ginsenoside Rh2 in ginseng induced apoptosis and paraptosis-like cell death in colon cancer cells [16]. Ginsenoside Rh2 levels are low in untreated ginseng, but after steaming, Rh2 levels increase [17]. In a recent review of the relationship between the structure and function of

\section{Biomed Central}


ginsenosides, we proposed that reducing sugar molecules in ginsenosides increases their anticancer bioactivity [7]. We also observed that further heat treatment of ginseng initiated the conversion of Rh2 to protopanaxadiol (PPD). In this transformation, another sugar molecule is removed from Rh2 (see Discussion and Figure 1).

PPD possesses anticancer potential because it induces cell apoptosis, a programmed cell death that is caspasedependent [18]. Paraptosis, another type of cell death, is characterized by the accumulation of cytoplasmic vacuoles and mitochondrial swelling [19]. Whether PPD-induced cell death also is mediated by caspase-independent paraptosis, like Rh2, is not known. In previous studies, Rh2 increased levels of reactive oxygen species (ROS) and activated the NF- $\kappa B$ survival pathway [16]. It would be interesting to know whether ROS blockage and inhibition of NF- $\kappa B$ signaling increases PPD-induced cell death and whether PPD's effect is enhanced by antioxidants because antioxidant dietary supplements are often self-administered by cancer patients $[20,21]$. The present study data suggest that paraptosis and NF- $\mathrm{BB}$ activation are associated with PPD-induced cancer chemoprevention.

\section{Methods}

\section{Chemicals and reagents}

DMSO and other solvents were obtained from Fisher Scientific (Pittsburgh, PA). Trypsin, McCoy's 5A, Leibovitz's L-15 medium, fetal bovine serum (FBS), and penicillin/ streptomycin solution (200x) were obtained from Mediatech, Inc. (Herndon, VA). N-Acetyl-L-cysteine (NAC), PS1145, propidium iodide (PI) and RNase were obtained from Sigma (St. Louis, MO). NAC, which is an antioxidant, was dissolved in the growth medium. PS-1145, a specific inhibitor of the NF-kB pathway, was dissolved in DMSO as a $20 \mathrm{mM}$ stock buffer. Protopanaxadiol (PPD) was obtained from National Institutes for Food

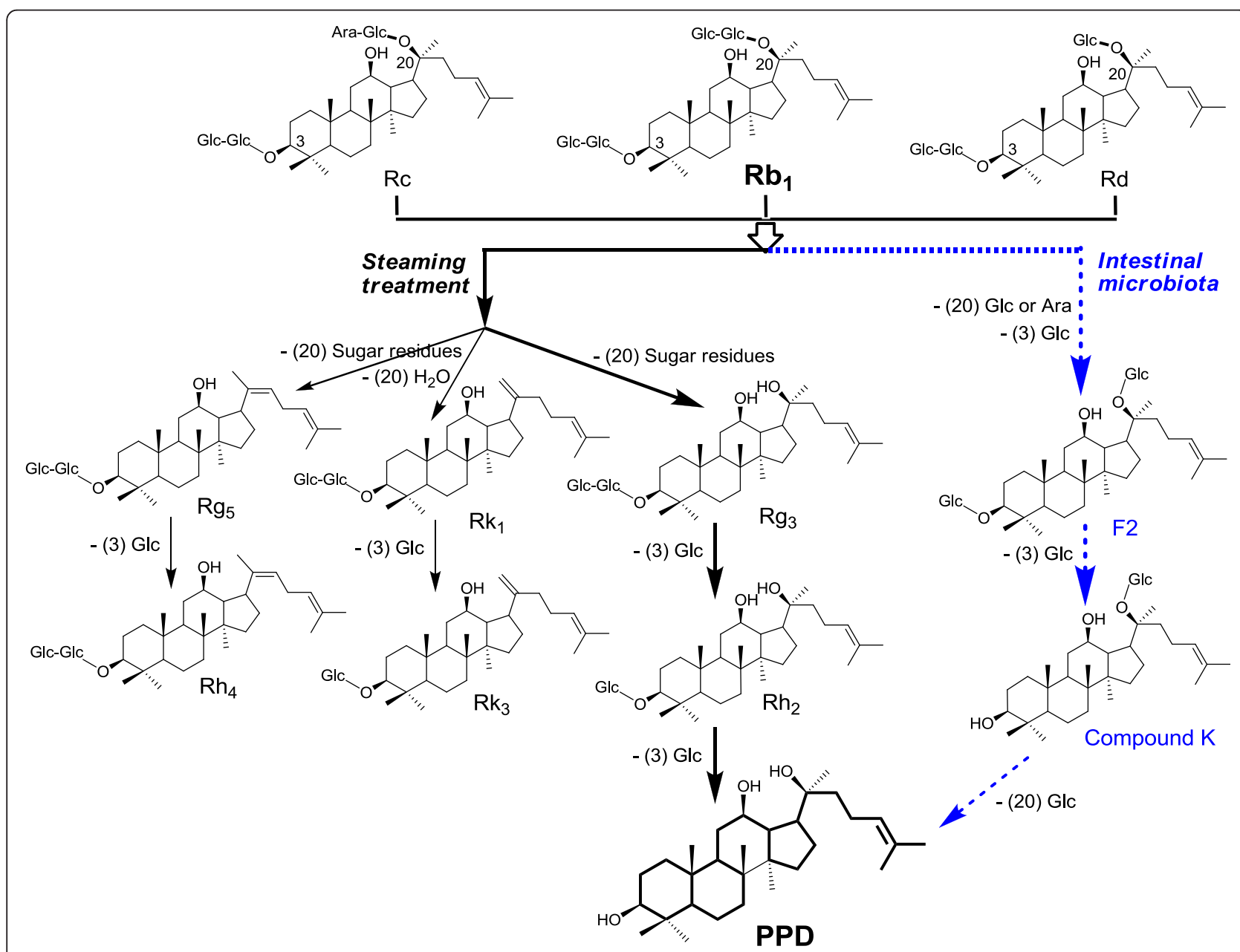

Figure 1 Transformation pathways of panaxadiol group ginsenosides $\mathrm{Rb} 1$, Rc and Rd by steaming treatment and intestinal microbiota. During steaming, ginsenosides Rb1, Rc and Rd are mainly transformed to Rg5, Rk1, and Rg3. Rg3 then converts to Rh2 and PPD. In addition, intestinal microbiota metabolize Rb1, Rc and Rd to compound K, which can be further converted to PPD (dotted lines). 
and Drug Control (Beijing, China). 5-Fluorouracil (5-FU) was obtained from American Pharmaceutical Partners Inc. (Schaumburg, IL). Luciferase assay kits were obtained from Promega (Madison, WI). Annexin V Apoptosis Kit was purchased from BD Biosciences (San Diego, CA). Reactive oxygen species (ROS) dye $2^{\prime}, 7^{\prime}$-dichlorodihydrofluorescein diacetate (H2DCFDA) and L-glutamine were obtained from Invitrogen (Carlsbad, CA).

\section{Cell culture}

Human colorectal cancer cells HCT-116 and SW-480 were obtained from the American Type Culture Collection (ATCC, Manassas, VA), and were maintained in McCoy's 5A (HCT-116) or Leibovitz's L-15 (SW-480) medium supplemented with $5 \%$ fetal bovine serum, 50 IU of penicillin/streptomycin and $2 \mathrm{mmol} / \mathrm{L}$ of L-glutamine in a humidified atmosphere with $5 \% \mathrm{CO}_{2}$ at $37^{\circ} \mathrm{C}$.

\section{Cell death assay}

Cells were seeded into 24 -well plates $\left(2 \times 10^{5}\right.$ cells/well). Samples were prepared based on the instruction provided with the Annexin V Apoptosis Kit. Briefly, after treatment as indicated in the result section, the adherent and detached cells were collected and washed twice with binding buffer containing $10 \mathrm{mM}$ HEPES, pH 7.4, $140 \mathrm{mM} \mathrm{NaCl}, 2.5 \mathrm{mM} \mathrm{CaCl}$, and then $1 \times 10^{5}$ cells were resuspended in $100 \mu \mathrm{l}$ of binding buffer. $5 \mu \mathrm{l}$ of annexin $\mathrm{V}$-FITC and $10 \mu \mathrm{l}$ of propidium iodide $(50 \mu \mathrm{g} / \mathrm{ml}$, stocking concentration) were added to the cell suspension. After gently mixing, the cells were incubated for $15 \mathrm{~min}$ at room temperature, and then $400 \mu$ l of binding buffer was added to get the sample ready. Quantification of cell death was performed using a FACScan flow cytometer (BD Biosciences, San Jose, CA). All the data analyses were performed using FlowJo analysis software, version 6.0 (FlowJo LLC, Ashland, OR). Annexin V-positive and/ or PI-positive cells were considered as cell death.

\section{Cell cycle analysis}

Cells were seeded in 24-well plates $\left(2 \times 10^{5}\right.$ cells/well). After $48 \mathrm{~h}$ of drug exposure or control conditions, cells were fixed gently by adding $80 \%$ ethanol before they were placed in a freezer for $2 \mathrm{~h}$; then cells were treated with $0.25 \%$ Triton X-100 for $5 \mathrm{~min}$ in an ice bath. The cells were resuspended in $130 \mu \mathrm{l}$ of PBS. Then, $5 \mu \mathrm{l}$ of PI/ RNase staining solution was added to the cell suspension. Cells were incubated in a dark room for $10 \mathrm{~min}$ at room temperature and analyzed using a FACScan flow cytometer.

\section{Crystal violet staining assay}

HCT-116 cells were seeded in 24-well plates $\left(1 \times 10^{5}\right.$ cells/ well). After $12 \mathrm{~h}$ of drug exposure or control conditions, the medium was removed and the cells were washed and stained with $0.2 \%$ crystal violet in $10 \%$ phosphate-buffered formaldehyde for $2 \mathrm{~min}$. The staining solution was removed and the cells were washed twice with PBS. The remaining cells adhering to the wells were observed under the microscope and photographed.

\section{Mitochondrial swelling assay}

Human liver mitochondria were obtained from Xenotech LLC (Lenexa, KS). Before the experiment, the mitochondria were suspended in $230 \mathrm{mM}$ mannitol, $70 \mathrm{mM}$ sucrose, $10 \mathrm{mM}$ Tris- $\mathrm{HCl}$, and $1 \mathrm{mM}$ EDTA, with a protein concentration of $0.5 \mathrm{mg} / \mathrm{ml}$. After exposure to $35 \mu \mathrm{M}$ of PPD or control condition at $25^{\circ} \mathrm{C}$, mitochondrial swelling was measured by the ultraviolet-visible spectrophotometry method. The absorbance changes at $540 \mathrm{~nm}$ were monitored [22].

\section{Intracellular ROS assay}

Intracellular ROS production was monitored by the permeable fluorescence dye, H2DCFDA. H2DCFDA can readily react with ROS to form the fluorescent product 2,7-dichlorofluorescein (DCF). The intracellular fluorescence intensity of DCF is proportional to the amount of ROS generated by the cells. After the indicated treatment, the cells were incubated with $10 \mu \mathrm{M}$ of H2DCFDA for thirty minutes and then cells were harvested and resuspended in PBS $\left(10^{6}\right.$ cells $\left./ \mathrm{mL}\right)$. The fluorescence intensity of intracellular DCF (excitation $488 \mathrm{~nm}$, emission $530 \mathrm{~nm}$ ) was measured using a FACScan flow cytometer.

\section{Luciferase activity assay}

The plasmids containing the luciferase reporter gene with or without a NF- $\mathrm{kB}$ response element and phRL-TK plasmid for the transfection control were donated by Liao's lab (Ben May Department for Cancer Research, University of Chicago). $10^{4}$ cells were seeded into 48 -well plates for $24 \mathrm{~h}$ and were co-transfected with $0.5 \mu \mathrm{g}$ of plasmid containing report construct and $10 \mathrm{ng}$ of phRL-TK using transfection reagent Effectene (Qiagen, Chatsworth, CA). At $24 \mathrm{~h}$ post-transfection, the cells were treated as desired. Luciferase activity was measured with a commercial kit (Promega Dual luciferase II) on a Monolight luminometer (Becton Dickinson, Franklin Lakes, NJ).

\section{Statistical analysis}

All experiments were performed in triplicate. The data are presented as mean \pm standard error (SE). A one-way ANOVA determined whether the results had statistical significance. In some cases, a Student's $t$-test was used for comparing two groups. The level of statistical significance was set at $P<0.05$. 


\section{Results}

Effects of PPD on cell death and cell cycle of human colorectal cancer cells

We used two human colorectal cancer cell lines, HCT116 and SW-480, to evaluate the effect of PPD on induction of cell death. As shown in Figure 2, for HCT-116 cells, treatment with 30,35 and $40 \mu \mathrm{M}$ of PPD for $48 \mathrm{~h}$ induced $20.9 \pm 1.7 \%, 50.4 \pm 3.9 \%$ and $74.2 \pm 3.4 \%$ cell death, respectively (all $P<0.01$ vs. control, $6.5 \pm 1.5 \%$ ). Similar effects were observed in SW-480 cells (Figure 2A). PPD significantly induced cell death in both of the cell lines in a concentration-dependent manner. As a positive control, we also tested the effect of 5-FU, a commonly used chemotherapeutic agent against colorectal cancer, on the induction of cell death (Figure 2B). The data show that, when comparable concentrations were used, the effect of PPD was stronger than that of 5-FU, suggesting that PPD could be a potential colorectal cancer chemopreventive compound.

PPD's effect on the cancer cell cycle is illustrated in Figure 3. Compared to control (G1 36.1\%, S 33.4\% and G2/M 25.1\% for HCT-116; G1 47.2\%, S 28.5\% and G2/ M 16.9\% for SW-480), 10 and $20 \mu \mathrm{M}$ of PPD did not change the cell cycle profile. Treatment with $30 \mu \mathrm{M}$ of PPD for $48 \mathrm{~h}$ changed the cell cycle profile, with G1 $55.8 \%, \mathrm{~S} 18.9 \%$ and G2/M $14.8 \%$ for HCT-116 cells; G1 $62.2 \%, \mathrm{~S} 11.8 \%$ and $\mathrm{G} 2 / \mathrm{M} 14.5 \%$ for SW-480. In both HCT-116 and SW-480 cells, PPD obviously increased cell fractions in the $\mathrm{G} 1$ phase.

\section{PPD-induced paraptosis-like cell death}

To explore the potential mechanism through which PPD induced cell death, morphological observation was conducted after crystal violet staining. As shown in Figure 4A, after treatment with $35 \mu \mathrm{M}$ of PPD for $24 \mathrm{~h}$, cytoplasmic vacuolization was significant. HCT-116 cells treated with vehicle control did not show vacuoles. When the PPD concentration was increased, the fraction of cells with cytoplasmic vacuolization increased (Figure 4B). Visible cytoplasmic vacuolization is a typical feature of paraptosis. Induction of paraptosis requires new protein synthesis but resists inhibition by caspase inhibitors. Pre-treatment of HCT-116 cells with cycloheximide (Cyclo), a protein synthesis inhibitor, blocked PPD-induced vacuole formation (Figure 4A). In addition to the formation of vacuoles in the cytoplasm, paraptosis is also characterized by mitochondrial swelling [8]. As illustrated in Figure 4C, PPD significantly induced mitochondrial swelling by monitoring absorbance at $540 \mathrm{~nm}$ in isolated human liver mitochondria. Thus, PPD induced cancer cell death in part via paraptosis.

\section{Effects of PPD on induction of ROS}

We measured ROS levels in colorectal cancer cells after treatment with PPD to determine if the compound induced ROS. To evaluate time-dependent activity, HCT116 cells were treated with $35 \mu \mathrm{M}$ of PPD, and ROS levels were measured at different time points. After treatment with PPD for $6 \mathrm{~h}$, ROS level was significantly higher than in the control. Thus, the $6 \mathrm{~h}$ time point was chosen (Figure 5A). Using two cell lines, HCT-116 and SW-480, ROS levels were determined after treatment with $20-40 \mu \mathrm{M}$ of PPD. As shown in Figure $5 \mathrm{~B}$ and $5 \mathrm{C}$, PPD significantly induced ROS production at $6 \mathrm{~h}$ in a concentration-dependent manner in both cell lines. These results suggest that PPD induced ROS production in human colorectal cancer cells.

\section{PPD activated the NF-KB pathway linked to ROS generation}

Ginseng-induced ROS promotes cell survival in colorectal cancer cells via activation of the NF-kB pathway. To determine whether PPD-induced ROS also activates the NF- $\kappa B$ pathway, we measured NF- $\kappa B$ reporter activity after treating HCT-116 cells with PPD. At the same concentration that led to high levels of ROS (Figure 5), PPD significantly induced NF- $\mathrm{B}$ reporter activity (Figure 6A).
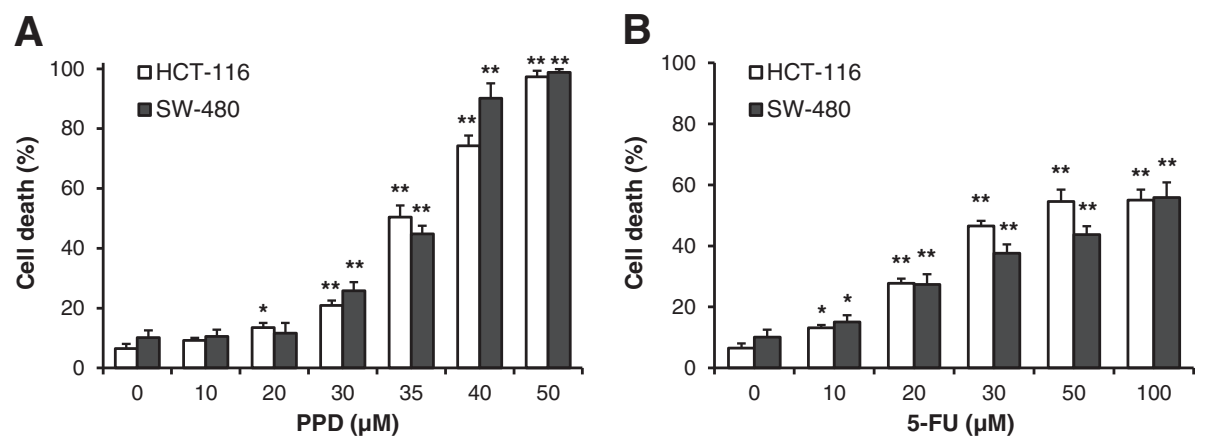

Figure 2 Effects of PPD and 5-FU on cell death in two human colorectal cancer cell lines. (A) Effects of PPD (10-50 $\mu$ M) on HCT-116 and SW-480 cell death. (B) Effects of 5-FU (10-100 $\mu \mathrm{M})$ on HCT-116 and SW-480 cell death. Cell death in the presence of PPD or 5-FU was measured after $48 \mathrm{~h}$ treatment. Data are presented as the mean \pm standard error. ${ }^{*} P<0.05,{ }^{*} P<0.01 \mathrm{vs}$. control. 

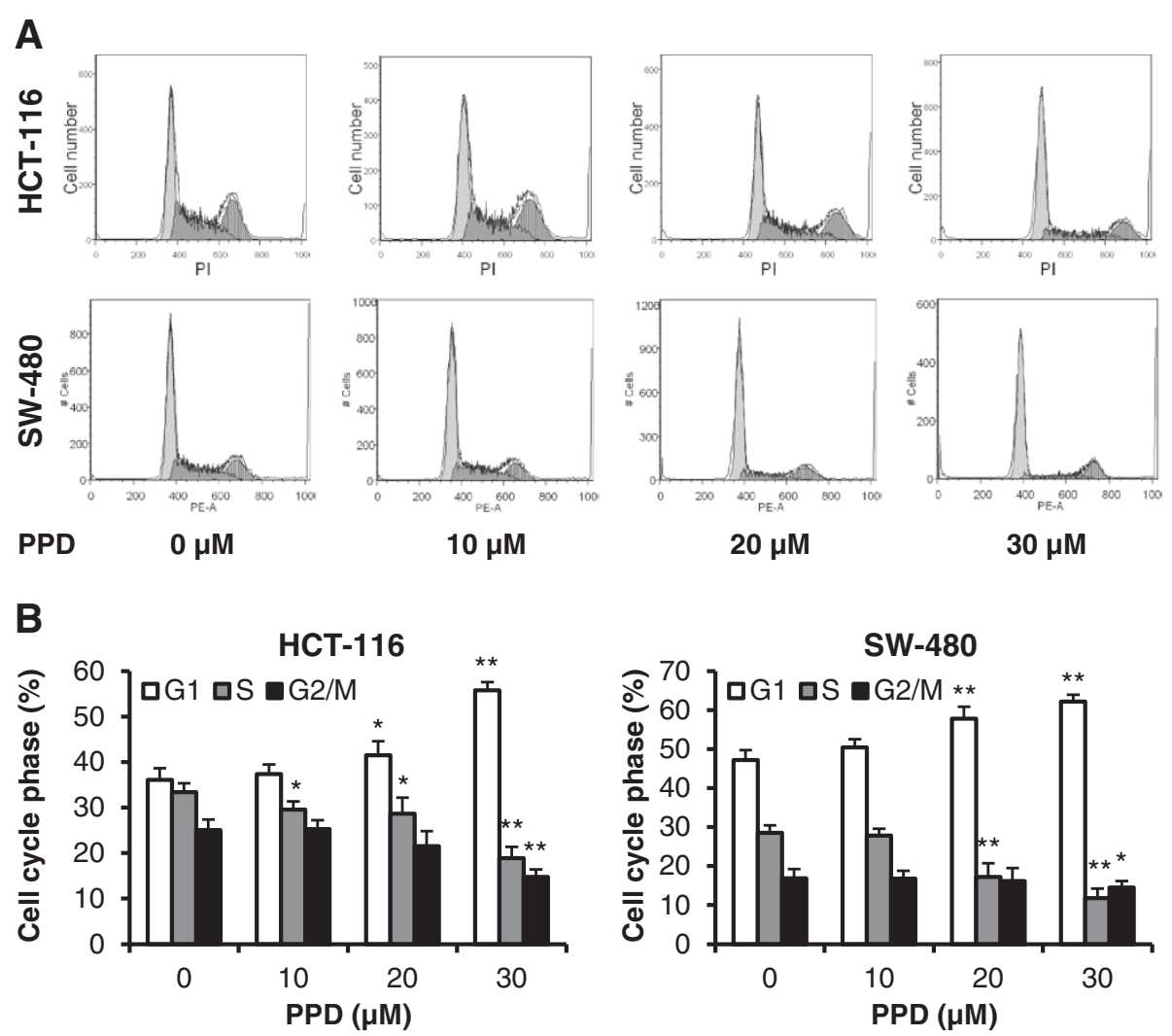

Figure 3 Effects of PPD on colorectal cancer cell cycle. HCT-116 and SW-480 cells were treated with 10-30 $\mu M$ PPD for 48 h, then fixed in ethanol and stained with propidium iodide. DNA content was determined by flow cytometry. (A) Representative histograms of DNA content in each experimental group. (B) Percentage of each cell cycle phase with various treatments. Data are presented as the mean \pm standard error. ${ }^{*} P<0.05,{ }^{*} P<0.01$ vs. control.

Decreasing the level of ROS in the cell should decrease NF- $\mathrm{kB}$ reporter activity, assuming that increased levels of ROS are required to induce NF-kB signaling. Addition of the antioxidant NAC significantly blocked the PPD-mediated induction of NF- $\mathrm{kB}$ transcriptional activity (Figure 6B) and increased cell death in HCT-116 cells, suggesting that PPD-induced ROS contribute to the activation of the NF- $\mathrm{kB}$ pathway.

We expected that the activated NF- $\kappa B$ pathway would counteract PPD-induced cell death in colorectal cancer cells because a decrease in ROS decreases NF- $\mathrm{kB}$ transcriptional activity. To further test the relationship of PPD-induced NF- $k B$ activation and cell death, we inhibited the NF- $\mathrm{BB}$ pathway by adding PS-1145, a specific inhibitor of the NF- $\mathrm{kB}$ pathway, to PPD-treated HCT-116 cells. PS-1145 significantly inhibited both basal and PPD-induced NF-kB transcriptional activity (Figure 6C), and increased PPD-induced cell death in HCT-116 cells. PPD-induced ROS contributed to the survival of colorectal cancer cells via activation of the NF- $\mathrm{kB}$ pathway. Therefore, PPD-induced colorectal cancer cell death is enhanced by antioxidants or an NF-kB inhibitor.

\section{Discussion}

After several years of cultivation in China or Korea, the root of Asian ginseng is harvested and steamed at standard boiling temperature; the steamed root is called red ginseng. It is believed that the steaming changes the ginsenoside composition profile, improving pharmacological activities. Our group used controlled variable steaming parameters to treat American ginseng and notoginseng to obtain desired ginsenoside profiles for increasing cancer chemopreventive effects $[14,15]$.

American ginseng is a commonly used dietary supplement in United States. The major ginsenosides in American ginseng belong to the protopanaxadiol group and include Rb1, Rc and Rd [23]. Ginsenoside Rb1 is the most abundant ginsenoside in American ginseng, accounting for over $50 \%$ of total ginsenosides in many samples. Figure 1 elucidates the ginsenoside transformation by steaming treatment and intestinal microbiota. During steaming treatment, the protopanaxadiol group of ginsenosides are mainly transformed via three pathways: 1) to $\operatorname{Rg} 5$ and then to $R h 4 ; 2)$ to $R k 1$ and then to $\mathrm{Rk} 3$; and 3) a major route, to $\mathrm{Rg} 3, \mathrm{Rh} 2$, and then to 

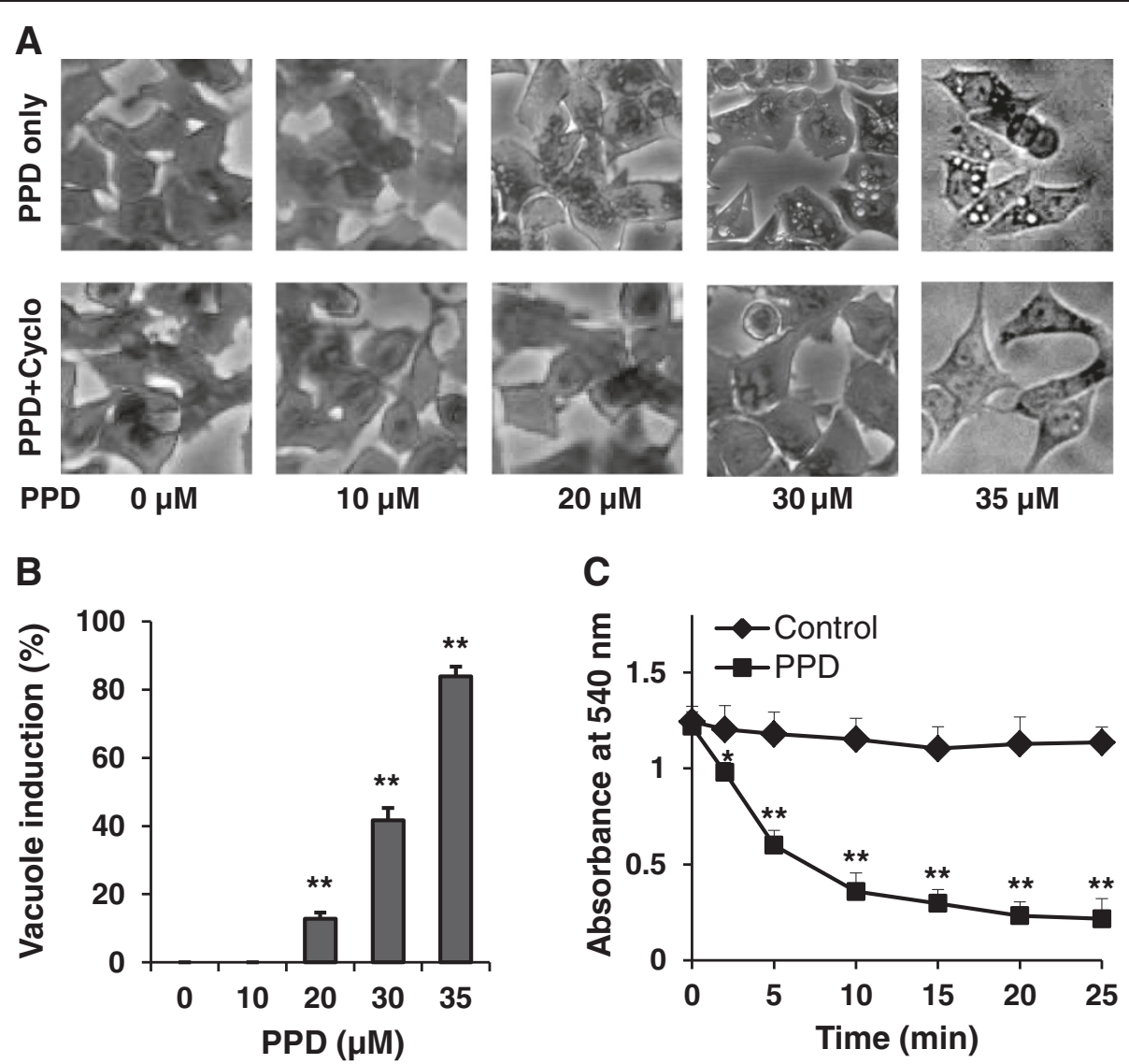

Figure 4 Induction of PPD on paraptosis-like cell death. (A) HCT-116 cells were treated with 10-35 $\mu \mathrm{M}$ of PPD in combination with or without $10 \mu \mathrm{g} / \mathrm{ml}$ of cycloheximide (Cyclo) for $24 \mathrm{~h}$, and then pictured. (B) The percentage of cytoplasmic vacuoles with 10-35 $\mu \mathrm{M}$ of PPD. (C) Mitochondrial swelling induced by $35 \mu \mathrm{M}$ of PPD observed by monitoring absorbance at $540 \mathrm{~nm}$ in isolated human liver mitochondria. Data are presented as the mean \pm standard error. ${ }^{*} P<0.05,{ }^{* *} P<0.01$ vs. control.

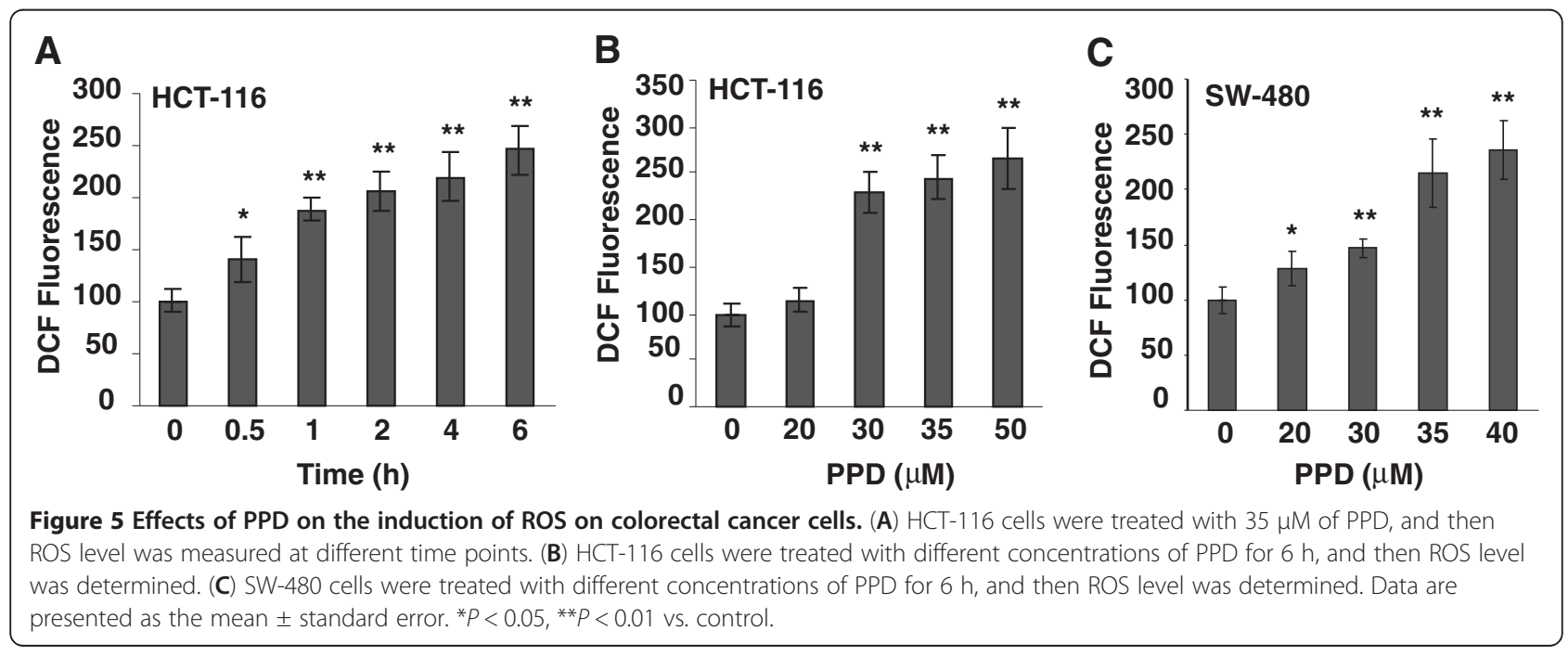



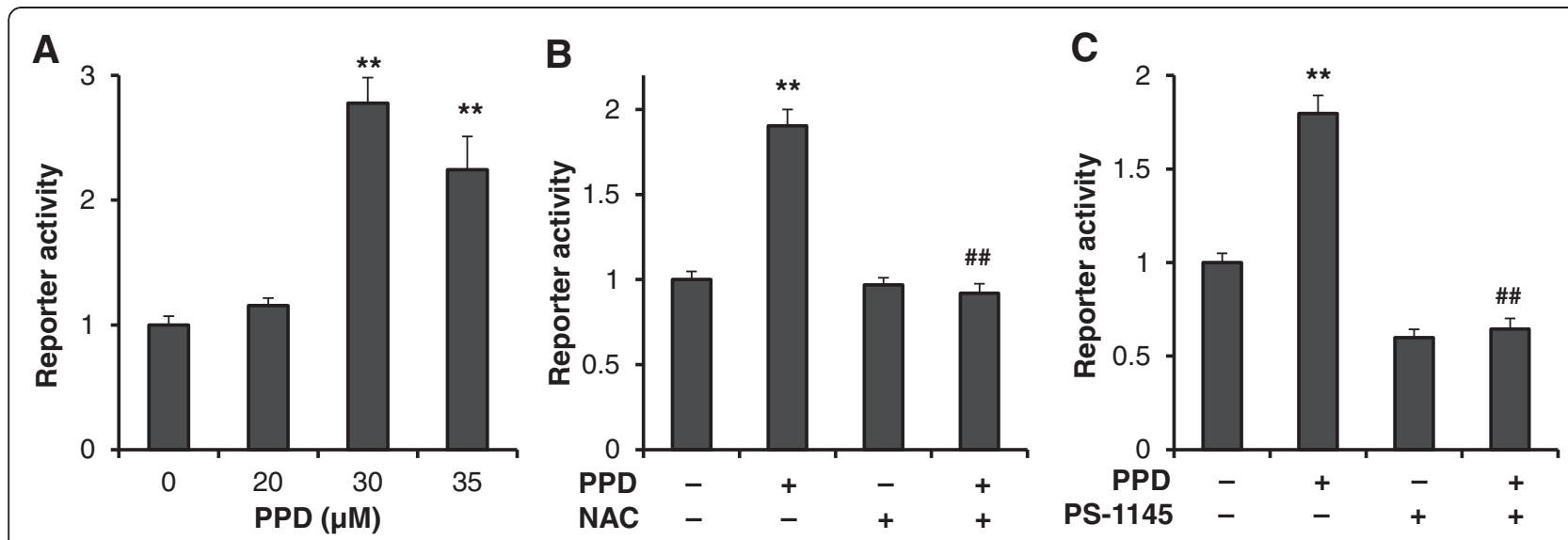

Figure 6 PPD activated the NF-KB pathway via ROS generation. (A) $24 \mathrm{~h}$ after transient transfection of NF-KB reporter plasmids, HCT-116 cells were treated with different concentrations of PPD for $24 \mathrm{~h}$ before the luciferase reporter activity was determined. (B) HCT-116 cells were treated with $35 \mu \mathrm{M}$ of PPD for $24 \mathrm{~h}$ in the presence or absence of NAC $(10 \mathrm{mM})$. (C) HCT-116 cells were treated with $35 \mu \mathrm{M}$ of PPD for $24 \mathrm{~h}$ in the presence or absence of PS-1145 $(50 \mu \mathrm{M})$. Data are presented as the mean \pm standard error. ${ }^{* *} P<0.01$ vs. control; \#\#P $<0.01$ vs. PPD only.

PPD [15,24]. Interestingly, after oral ginseng administration, gut microbiota, which normally exist in the gastrointestinal tract, can convert Rb1 and other protopanaxadiol group ginsenosides into their metabolite, ginsenoside compound K (CK) $[25,26]$. Recently, our study data showed that a relatively high amount of CK could be transformed to PPD by gut microbiota (unpublished data). Thus, the evaluation of cancer chemopreventive effects of PPD and its related mechanism of action is particularly pertinent to ginseng anticancer investigations.

Two representative human cancer cell lines, HCT-116 and SW-480, which differ in the expression of the p53 tumor suppressor gene, were used in our cell death observation. HCT-116 is p53 wild-type, while SW-480 has mutated p53. Tumor suppressor gene p53 is thought to be important in the cellular response to chemotherapeutic agent-induced damage. Mutation in p53 has been shown to correlate with an increased resistance to chemotherapy in cancer cells [27]. Our results showed that PPD significantly induced cell death in these two cell lines in a concentration-dependent manner, and HCT-116 was more sensitive even at lower concentrations. After PPD treatment, accumulation of cytoplasmic vacuoles was observed in the cancer cells, suggesting that paraptosis, another type of programmed cell death [19], was associated with PPD's effect. Paraptosis is further supported by a mitochondrial swelling assay and by the observation that PPD used in combination with cycloheximides, a protein synthesis inhibitor, blocked PPD-induced vacuole formation.

5-Fluorouracil (5-FU) is a chemotherapeutic agent widely used for cancers of different organs including colorectum [28]. The clinical response rate of 5-FU in colorectal cancer treatment was $20-30 \%$, and in combination with irinotecan or oxaliplatin, up to $50 \%[29,30]$. Consistent with others [31], we observed that the cell death induction of 5-FU is not very impressive, with apoptosis as a main cellular response to treatment with 5-FU. At comparable concentrations, our data showed that PPD more significantly induced cell death. It is crucial for future work to identify combinatory therapies of natural product-derived compounds to increase the effectiveness of 5-FU on human colorectal cancer.

Our data showed that in both tested colon cancer cell lines, PPD significantly induced ROS production. Further, PPD activated the NF- $\mathrm{KB}$ pathway, which is linked to ROS generation. When the antioxidant NAC was used, NF- $\mathrm{BB}$ reporter activity levels were significantly reduced. This observation suggested that co-administration of PPD and a botanical antioxidant may achieve better cancer chemopreventive effects. Panaxadiol (PD) is a purified sapogenin of ginseng saponins, which has exhibited significant anticancer activity [11]. Structurally, PD is very similar to PPD, with basically only side chain cyclization [23]. Epigallocatechin gallate (EGCG), a major catechin in green tea, is a strong botanical antioxidant. Recently, we reported synergistic anticancer effects of PD and EGCG [32]. Based on the similar chemical structure of PD and PPD, it would be expected that co-administration of PPD and EGCG could also initiate increased cancer chemoprevention activities.

\section{Conclusions}

Results from the present study suggest that paraptosis and NF- $\mathrm{BB}$ activation are associated with PPD-induced cancer chemoprevention. The activation of PPD's NF- $\mathrm{kB}$ pathway is linked to its increased ROS level.

\section{Competing interests}

The authors declare that they have no competing interests. 


\section{Authors' contributions}

CZW, TCH, WD and CSY designed the study, set up the experiments, participated in data collection, analyzed and interpreted the results, and drafted the manuscript. $B L, X D W, Z Z$ and $C Y$ carried out experiments and participated in data interpretation. TDC edited the manuscript. All authors read and approved the final manuscript.

\section{Acknowledgements}

This work was supported in part by the NIH/NCCAM AT004418 and AT005362, NIH GM074197 and 5P30DK042086, NIH/NCI CA149275, and DOD W81XWH-10-1-0077.

\section{Author details}

${ }^{1}$ Tang Center for Herbal Medicine Research, University of Chicago, Chicago, IL, USA. ${ }^{2}$ Department of Anesthesia and Critical Care, University of Chicago, Chicago, IL, USA. ${ }^{3}$ Ben May Department for Cancer Research, University of Chicago, Chicago, IL, USA. ${ }^{4}$ Department of Surgery, University of Chicago, Chicago, IL, USA. ${ }^{5}$ Committee on Clinical Pharmacology and Pharmacogenomics, University of Chicago, Chicago, IL, USA. ${ }^{6}$ Tang Center for Herbal Medicine Research, and Department of Anesthesia \& Critical Care, Pritzker School of Medicine, University of Chicago, 5841 S. Maryland Ave., MC 4028, Chicago, IL 60637, USA.

Received: 4 October 2012 Accepted: 19 December 2012

Published: 3 January 2013

\section{References}

1. Wood CG: Multimodal approaches in the management of locally advanced and metastatic renal cell carcinoma: combining surgery and systemic therapies to improve patient outcome. Clin Cancer Res 2007, 13(2 Pt 2):697s-702s.

2. Oettle H, Post S, Neuhaus P, Gellert K, Langrehr J, Ridwelski K, Schramm H, Fahlke J, Zuelke C, Burkart C, Gutberlet K, Kettner E, Schmalenberg H, Weigang-Koehler K, Bechstein WO, Niedergethmann M, Schmidt-Wolf I, Roll $L$, Doerken B, Riess H: Adjuvant chemotherapy with gemcitabine vs observation in patients undergoing curative-intent resection of pancreatic cancer: a randomized controlled trial. JAMA 2007, 297(3):267-277.

3. Biagi JJ, Raphael MJ, Mackillop WJ, Kong W, King WD, Booth CM: Association between time to initiation of adjuvant chemotherapy and survival in colorectal cancer: a systematic review and meta-analysis. JAMA 2011, 305(22):2335-2342.

4. Wang CZ, Calway T, Yuan CS: Herbal medicines as adjuvants for cancer therapeutics. Am J Chin Med 2012, 40(4):657-669.

5. Bougnoux P, Hajjaji N, Maheo K, Couet C, Chevalier S: Fatty acids and breast cancer: sensitization to treatments and prevention of metastatic re-growth. Prog Lipid Res 2010, 49(1):76-86.

6. Lee KH: Discovery and development of natural product-derived chemotherapeutic agents based on a medicinal chemistry approach. J Nat Prod 2010, 73(3):500-516.

7. Qi LW, Wang CZ, Yuan CS: American ginseng: potential structure-function relationship in cancer chemoprevention. Biochem Pharmacol 2010, 80(7):947-954.

8. Xu Z, Chen X, Zhong Z, Chen L, Wang Y: Ganoderma lucidum polysaccharides: immunomodulation and potential anti-tumor activities. Am J Chin Med 2011, 39(1):15-27.

9. Yun TK: Panax ginseng-a non-organ-specific cancer preventive? Lancet Oncol 2001, 2(1):49-55

10. Yun TK, Zheng S, Choi SY, Cai SR, Lee YS, Liu XY, Cho KJ, Park KY: Nonorgan-specific preventive effect of long-term administration of Korean red ginseng extract on incidence of human cancers. J Med Food 2010, 13(3):489-494

11. Li XL, Wang CZ, Mehendale SR, Sun S, Wang Q, Yuan CS: Panaxadiol, a purified ginseng component, enhances the anti-cancer effects of 5-fluorouracil in human colorectal cancer cells. Cancer Chemother Pharmacol 2009, 64(6):1097-1104.

12. Fishbein $A B$, Wang $C Z$, Li $X L$, Mehendale SR, Sun S, Aung HH, Yuan CS Asian ginseng enhances the anti-proliferative effect of 5-fluorouracil on human colorectal cancer: comparison between white and red ginseng. Arch Pharm Res 2009, 32(4):505-513.

13. Hwang JW, Oh JH, Yoo HS, Lee YW, Cho CK, Kwon KR, Yoon JH, Park J, Her S, Lee ZW, Jang IS, Choi JS: Mountain ginseng extract exhibits anti- lung cancer activity by inhibiting the nuclear translocation of NF-kappaB. Am J Chin Med 2012, 40(1):187-202.

14. Wang CZ, Aung HH, Ni M, Wu JA, Tong R, Wicks S, He TC, Yuan CS: Red American ginseng: ginsenoside constituents and antiproliferative activities of heat-processed Panax quinquefolius roots. Planta Med 2007, 73(7):669-674.

15. Sun S, Qi LW, Du GJ, Mehendale SR, Wang CZ, Yuan CS: Red notoginseng: higher ginsenoside content and stronger anticancer potential than Asian and American ginseng. Food Chem 2011, 125(4):1299-1305.

16. Li B, Zhao J, Wang CZ, Searle J, He TC, Yuan CS, Du W: Ginsenoside Rh2 induces apoptosis and paraptosis-like cell death in colorectal cancer cells through activation of p53. Cancer Lett 2011, 301(2):185-192.

17. Wang CZ, Zhang B, Song WX, Wang A, Ni M, Luo X, Aung HH, Xie JT, Tong R, He TC, Yuan CS: Steamed American ginseng berry: ginsenoside analyses and anticancer activities. J Agric Food Chem 2006, 54(26):9936-9942.

18. Du GJ, Dai Q, Williams S, Wang CZ, Yuan CS: Synthesis of protopanaxadiol derivatives and evaluation of their anticancer activities. Anticancer Drugs 2011, 22(1):35-45.

19. Chen TS, Wang XP, Sun L, Wang LX, Xing D, Mok M: Taxol induces caspase-independent cytoplasmic vacuolization and cell death through endoplasmic reticulum (ER) swelling in ASTC-a-1 cells. Cancer Lett 2008, 270(1):164-172.

20. Greenlee H, Gammon MD, Abrahamson PE, Gaudet MM, Terry MB, Hershman DL, Desai M, Teitelbaum SL, Neugut Al, Jacobson JS: Prevalence and predictors of antioxidant supplement use during breast cancer treatment: the Long Island Breast Cancer Study Project. Cancer 2009, 115(14):3271-3282.

21. Myung SK, Kim Y, Ju W, Choi HJ, Bae WK: Effects of antioxidant supplements on cancer prevention: meta-analysis of randomized controlled trials. Ann Oncol 2010, 21(1):166-179.

22. Fernandez-Gomez FJ, Galindo MF, Gomez-Lazaro M, Gonzalez-Garcia C Cena V, Aguirre N, Jordan J: Involvement of mitochondrial potential and calcium buffering capacity in minocycline cytoprotective actions. Neuroscience 2005, 133(4):959-967.

23. Qi LW, Wang CZ, Yuan CS: Ginsenosides from American ginseng: chemical and pharmacological diversity. Phytochemistry 2011, 72(8):689-699.

24. Qi LW, Wang CZ, Yuan CS: Isolation and analysis of ginseng: advances and challenges. Nat Prod Rep 2011, 28(3):467-495.

25. Wang CZ, Kim KE, Du GJ, Qi LW, Wen XD, Li P, Bauer BA, Bissonnette MB, Musch MW, Chang EB, Yuan CS: Ultra-performance liquid chromatography and time-of-flight mass spectrometry analysis of ginsenoside metabolites in human plasma. Am J Chin Med 2011, 39(6):1161-1171

26. Wang HY, Qi LW, Wang CZ, Li P: Bioactivity enhancement of herbal supplements by intestinal microbiota focusing on ginsenosides. Am J Chin Med 2011, 39(6):1103-1115.

27. Din FV, Dunlop MG, Stark LA: Evidence for colorectal cancer cell specificity of aspirin effects on NF kappa B signalling and apoptosis. $\mathrm{Br} J$ Cancer 2004, 91(2):381-388.

28. Longley DB, Harkin DP, Johnston PG: 5-fluorouracil: mechanisms of action and clinical strategies. Nat Rev Cancer 2003, 3(5):330-338.

29. Douillard JY, Cunningham D, Roth AD, Navarro M, James RD, Karasek $P$, Jandik P, Iveson T, Carmichael J, Alakl M, Gruia G, Awad L, Rougier P: Irinotecan combined with fluorouracil compared with fluorouracil alone as first-line treatment for metastatic colorectal cancer: a multicentre randomised trial. Lancet 2000, 355(9209):1041-1047.

30. Giacchetti S, Perpoint B, Zidani R, Le Bail N, Faggiuolo R, Focan C, Chollet $P$, Llory JF, Letourneau Y, Coudert B, Bertheaut-Cvitkovic F, Larregain-Fournier D, Le Rol A, Walter S, Adam R, Misset JL, Levi F: Phase III multicenter randomized trial of oxaliplatin added to chronomodulated fluorouracilleucovorin as first-line treatment of metastatic colorectal cancer. J Clin Oncol 2000, 18(1):136-147.

31. Choudhary B, Hanski ML, Zeitz M, Hanski C: Proliferation rate but not mismatch repair affects the long-term response of colon carcinoma cells to 5FU treatment. Cancer Lett 2012, 320(1):56-64.

32. Du GJ, Wang CZ, Qi LW, Zhang ZY, Calway T, He TC, Du W, Yuan CS: The synergistic apoptotic interaction of panaxadiol and epigallocatechin gallate in human colorectal cancer cells. Phytother Res 2012, 26. doi:10.1002/ptr.4707. In press.

doi:10.1186/1472-6882-13-2

Cite this article as: Wang et al:: Paraptosis and NF-кB activation are associated with protopanaxadiol-induced cancer chemoprevention. BMC Complementary and Alternative Medicine 2013 13:2. 